\title{
ÁMBITOS DE INTERVENCIÓN EN EDUCACIÓN NO FORMAL. UNA PROPUESTA TAXONÓMICA
}

\author{
Fields of action in Non Formal Education. \\ A suggested taxonomy
}

$M^{\mathrm{a}}$. Inmaculada PASTOR HOMS

Facultad de Educación. Universidad de las Islas Baleares. Campus Universitario. O7071 Palma de Mallorca

Fecha de aceptación definitiva: marzo de 2000.

BIBLID [(1130-3743) 11, 1999, 183-215]

RESUMEN

Dado el dinamismo y rápido crecimiento del sector educativo no formal, se nos plantea el reto de definir y aplicar con rigor unos criterios taxonómicos suficientemente globalizadores que permitan una ordenación descriptiva de la situación actual y posibiliten, además, una clarificación y análisis de los grandes campos de intervención en ENF posibles y probables en el futuro. Tras la revisión de algunas de las principales clasificaciones elaboradas al respecto, planteamos una propuesta taxonómica fundamentada en el análisis de necesidades educativas orientadas al desarrollo individual y social en sus múltiples facetas.

SUMMARY

The dynamism and growth of non formal education activities bring about the challenge of defining and applying some comprehensive taxonomycal criteria that allow us to do a descriptive layout of the present situation and a clarification of non formal education's fields of action in the future. After a critical review of some classifications concerning this subject, we present a suggested taxonomy based on the analysis of educational needs related to individual and social development. 


\section{INTRODUCCIÓN}

El sector educativo no formal ${ }^{1}$ presenta tal heterogeneidad y extensión que resulta difícil, no sólo caracterizarlo ${ }^{2}$, sino también elaborar taxonomías y clasificaciones que permitan incluir de manera exhaustiva, ordenada, coherente y comprensiva la amplia gama de manifestaciones y medios que abarca en la actualidad. Pero ello, siendo problemático, no es, a nuestro criterio, la dificultad principal, sino que creemos que dado el dinamismo y rápido crecimiento del sector -que se evidencia en la aparición constante de nuevas experiencias de educación no formal inexistentes hace unos pocos años-, la dificultad y el reto fundamental consiste en definir y aplicar con rigor unos criterios taxonómicos suficientemente globalizadores que, no solamente permitan una ordenación descriptiva de la situación actual (que en poco tiempo quedaría desfasada por el dinamismo del sector), sino que posibiliten, además, una clarificación y análisis de las grandes lineas o ámbitos de intervención en educación no formal posibles y probables en un futuro a corto y medio plazo. Es decir, creemos que la conveniencia de elaborar clasificaciones en el complejo mundo de la educación no formal, no debe únicamente justificarse en la necesidad de conocer de la manera más ordenada y completa posible la realidad del sector y, en base a ello, descubrir sus líneas o tendencias de actuación, sino que, merced a la utilización de unos criterios taxonómicos suficientemente amplios y claros, debe pretenderse la búsqueda de nuevas posibilidades de desarrollo de cara al futuro, detectando zonas y ámbitos de actuación sobredimensionados o, por el contrario, infravalorados o, simplemente, ignorados. Todo ello, evidentemente, sin ningún afán burocratizador ni centralizador, sino más bien, partiendo del respeto a la idiosincrasia de la educación no formal y en tanto que campo de aplicación de la teoría de la educación (A. COLOM, 1997, pp. 151-152), con el deseo de contribuir a la tarea de sugerir pautas de acción orientadas a la mejora, innovación y expansión de las práctica educativas no formales a las que otorgamos una extraordinaria relevancia en una sociedad en constante cambio que exige de los individuos y las colectividades un esfuerzo de aprendizaje permanente.

\footnotetext{
${ }^{1}$ Aunque no es nuestro propósito en este artículo tratar la cuestión conceptual, pues nos excederíamos en mucho del espacio del que disponemos, sí creemos imprescindible, al inicio de nuestro trabajo y dada la diversidad de matices que podemos apreciar en las distintas definiciones que se han dado de educación no formal, desde la primera de las que formulara Philip H. Coombs (Philip H. Coombs, Roy C. Prosser y Manzoor Ahmed, 1973 a) hasta hoy, aclarar nuestra propia concepción del término, que resumimos del siguiente modo: ENF comprende todo proceso educativo diferenciado de otros procesos, organizado, sistemático, planificado especificamente en función de unos objetivos educativos determinados, llevado a cabo por grupos, personas o entidades identificables y reconocidos, que no forme parte integrante del sistema educativo legalmente establecido y que, aunque esté relacionado con él, no proporcione directamente ninguno de sus grados o titulaciones.

${ }^{2}$ Por ese motivo, resultan especialmente destacables las propuestas de caracterización de la ENF elaboradas, entre otros, por A. Callaway (1976), R. Paulston (1976), Ph. H. Coombs (1991), D. J. Radcliffe y N. S. Colleta (1980,1989), C. Power (1991), J. Trilla (1993), A. Colom (1990), A. Sanvisens (1990), C. Scurati (1991), P. Ellis (1994).
} 


\section{ANÁLISIS DE ALGUNAS PROPUESTAS TAXONÓMICAS}

Diversos autores han elaborado propuestas más o menos concretas en relación a las áreas o ámbitos propios de la educación no formal, algunas de las cuales sintetizaremos a continuación con objeto, no de hacer una descripción exhaustiva de las mismas, sino de analizar los criterios utilizados en su planteamiento y señalar los que, a nuestro juicio, pueden resultar más clarificadores y útiles para alcanzar, a la vez, los propósitos descriptivos y prospectivos a los que nos referíamos antes.

Lo cierto es que la discusión acerca de los criterios a aplicar para determinar las categorías, tipos o ámbitos en que se puede clasificar la educación no formal se inicia simultáneamente a su proceso de construcción conceptual. Como ejemplo interesante de este discurso, citaremos a A. CALLAWAY (1973; edición traducida al castellano de 1976, pp. 39-40), quien al plantear sus "Fundamentos para una clasificación de la educación extraescolar", sugiere la aplicación de seis criterios, bien por separado o combinados entre sí:

1. agrupar por sus ocupaciones a quienes reciben la instrucción (directivos, agricultores...);

2. ordenar las clases de experiencias educativa (educación general, pre-laboral, perfeccionamiento profesional...);

3. considerar las instituciones que imparten la educación (teniendo en cuenta quien las dirige o bien describiéndolas);

4. tomar en cuenta la extensión del proceso educativo extraescolar (cursos prolongados o breves, educación permanente);

5. considerar el contenido que se transmite (general, técnico, instrucción cívica) $y$

6. considerar la relación directa o indirecta entre la creación de ocupaciones $y$ las perspectivas inmediatas de acrecentar la productividad económica.

Sin embargo, como constataremos a lo largo de las páginas que siguen, podemos afirmar que los criterios más frecuentemente utilizados para clasificar los ámbitos de educación no formal han sido:

- Los destinatarios de la actividad educativa,

- Los agentes de la actividad educativa (educadores)

- Las instituciones proveedoras de educación no formal

- Los contextos sociales en los que se desarrolla

- Las áreas funcionales que se cumplimentan

- Los aspectos metodológicos

- Los aspectos organizativos y económicos

- El grado de "formalización"de la actividad educativa.

De entre todos ellos, probablemente los más usuales hayan sido los relativos a los destinatarios, las instituciones, los contextos sociales y, sobre todo, las áreas 
funcionales, aunque este último criterio adquiera matices distintos según los autores, como iremos apreciando. Es el caso de Frederick J. HARBISON (1976, pp. 2223), quien considera que la educación no formal puede dividirse en tres grandes categorías, según la orientación o funcionalidad que asuma con respecto al mundo laboral fundamentalmente, distinguiendo entre:

a) actividades principalmente orientadas a desarrollar habilidades y conocimientos de los integrantes de la fuerza de trabajo que ya tienen empleo;

b) actividades que tienden especialmente a preparar a otras personas, en su mayoría jóvenes, para obtener un empleo; $y$

c) actividades tendientes a desarrollar habilidades, conocimientos y comprensión que trasciendan la esfera del trabajo ${ }^{3}$

Su coetáneo Archibald CALLAWAY (1976: 39-43), se decanta, en cambio, por una clasificación basada en el primer criterio que señalábamos, es decir, los destinatarios de la actividad educativa, utilizando en sus trabajos dos grandes categorías para tipificar la educación no formal:

a) Educación no formal para jóvenes (consistente básicamente en programas de educación general, educación técnico-laboral y educación civica).

b) Educación no formal para adultos (que abarca programas de alfabetización, alfabetización funcional, desarrollo comunitario, bigiene y sanidad, nutrición, actualización de conocimientos, formación en el trabajo, etc.).

Igualmente relacionada con este criterio está, sin duda, la propuesta de A. COLOM (1997: 151-152) quien afirma, en el marco de su enfoque de la teoría de la educación, que uen el campo de la educación no formal podemos distinguir dos grandes áreas de aplicación en función de la finalidad educativa con la que dotamos nuestros procesos: la social y la ambiental". Así pues, tendríamos un ámbito que integraría todos aquellos procesos educativos que van destinados a la mejora de la formación y condición social de los individuos (al que denomina educación social) y otro ámbito dirigido a la conservación y mejora del medio ambiente (que sería la edcación ambiental). En su propuesta, por tanto, vemos que el elemento que sirve para discriminar entre la amalgama de procesos educativos no formales cuya finalidad común y consustancial consiste en la mejora de la realidad existente, es, precisamente, el destinatario de dichos procesos: la sociedad o el medio

\footnotetext{
3 En la primera categoría incluye, por ejemplo, los programas de extensión agrícola y centros de formación de agricultores, los servicios de desarrollo de la comunidad rural, la capacitación dentro del horario de trabajo de artesanos en todo tipo de fabricación, el perfeccionamiento del personal en empresas, la educación laboral organizada por sindicatos, los sistemas de instrucción basados en el trabajo rentado como aprendiz, etc. En la segunda categoría se incluirían los programas de orientación vocacional, la instrucción en especialidades de las fuerzas armadas u otros programas que desarrollen capacidad para obtener empleos iniciales, etc. Finalmente, en la última categoría tendríamos los programas de alfabetización, nutrición, salud, economía doméstica, planificación familiar, educación política, etc.
} 
ambiente. En un trabajo anterior, sin embargo, (A. COLOM, 1987, pp. 23 y ss.), al acotar lo que denomina "contextos de intervención socioeducativa", señala tres posibles criterios taxonómicos, válidos tanto para la educación formal ("contexto escolar") como para la educación no formal ("contexto de la sociedad") a partir de los cuales elabora una amplia clasificación: a) los espacios orgánicos sociales, b) los espacios supraorgánicos o áreas funcionales y c) los espacios mixtos (orgánicos y supraorgánicos) o institucionales.

Por su parte, P. FURTER (1976, pp. 88 y ss.; 1980, pp. 157-191 y 311-332) opta por un criterio que podríamos denominar funcional-temático ${ }^{4}$ y en base a él, distingue dos grandes ámbitos en la educación no formal:

\section{a) un ámbito relacionado con la educación escolar y}

b) un ámbito que tiene finalidades propias y autónomas.

Dentro de cada uno de ellos establece distintas clasificaciones en base a funciones más específicas y, así, en el primer ámbito distingue entre procesos educativos cuyas funciones sean las de prolongar la educación formal, enriquecerla, sustituirla, recuperar a los estudiantes que tienen dificultades, integrar mejor a los estudiantes en ella, personalizar el aprendizaje o aproximarla a la vida práctica. Asimismo, en el ámbito definido como autónomo e independiente respecto al sector formal, sugiere, sin pretender la exhaustividad, diferentes áreas en función de que su finalidad sea la promoción de una vida social y comunitaria más rica, la formación política, el perfeccionamiento profesional, el cultivo del potencial creativo y expresivo o la mejora de los estilos de relación.

J. M. a QUINTANA y otros autores (1991) al describir el panorama general de lo que califican como "iniciativas sociales" de educación fuera de la escuela, utilizan indistintamente como criterios taxonómicos implícitos el relativo a los «agentes o promotores" de la actividad educativa, sean institucionales o no, (mencionando concretamente las iniciativas educativas de las bibliotecas públicas, los museos, las agrupaciones o asociaciones juveniles y los centros hospitalarios), el criterio "funcional-temático" (señalando en este aspecto las áreas de educación ambiental, educación para la salud, prevención y reeducación de la delincuencia, desarrollo comunitario y educación del ocio) y, por último, el criterio referente a los destinatarios particulares de la actividad educativa, en el que incluyen los ámbitos de la educación de adultos, la atención educativa a las víctimas del delito y, también, la reeducación de delincuentes.

${ }^{4}$ De los distintos autores que afirman utilizar el criterio "funcional" en sus propuestas taxonómicas podríamos distinguir entre aquéllos que hablan de "función" en tanto que orientación o finalidad de la actividad educativa no formal (orientadora, compensatoria, dinamizadora, sustitutoria...) sin vincularla a ningún contenido en concreto, y aquéllos que utilizan el término "función" asociándolo al campo temático (salud, consumo, patrimonio cultural, medio ambiente...) o vital (trabajo, ocio, vida familiar...) hacia el cual se dirige la oferta educativa. 
J. TRILLA (1993), aún admitiendo que las posibilidades taxonómicas son muy numerosas debido a la amplitud de criterios existentes ${ }^{5}$, considera que los más útiles y, por ende, más frecuentemente utilizados, son el criterio funcional-temático y el criterio relativo a los destinatarios. Respecto al primero, entiende que pueden destacarse, en general, cuatro tipos de funciones:

a) Funciones relacionadas con la educación formal, que pueden ser de suplencia, sustitución, refuerzo, compensación, etc.

b) Funciones relacionadas con el trabajo, que pueden dirigirse a la formación laboral, al reciclaje o perfeccionamiento, a la inserción, a la formación sindical o a diversos aspectos relacionados con el trabajo (salud, bigiene, seguridad...).

c) Funciones relacionadas con el ocio y la formación cultural desinteresada, como actividades artísticas, deportivas, de animación sociocultural, relacionadas con la pedagogía del ocio, etc.

d) Funciones relacionadas con otros aspectos de la vida cotidiana y social, como programas de educación sanitaria, de consumo, de formación de voluntariado, de padres, etc.

Dentro del segundo criterio establece como preferentes dos subcriterios: la edad de los destinatarios (infancia, juventud, adultez, tercera edad, todas las edades) y la especificidad de los mismos (público en general e individuos o grupos con características específicas). Combinando ambos, podemos distinguir diez diferentes tipos de programas, aunque las posibilidades combinatorias pueden exten-

${ }^{5}$ Da buena cuenta de esas posibilidades mediante el esquema que sintetizamos a continuación:

A) Aplicando el criterio de los destinatarios: Se puede distinguir entre programas dirigidos a la población en general y programas dirigidos a sectores específicos (según edad, profesión...)

B) Aplicando el criterio de los educadores:Se pueden diferenciar los programas según el grado de profesionalización y/o formación y titulación de los educadores.

C) Aplicando el criterio del contexto social en el que se desarrollan: Se pueden diferenciar entre programas para zonas desarrolladas, en vías de desarrollo o subdesarrolladas, para zonas urbanas, suburbiales o rurales.

D) Aplicando el criterio metodológico: Se pueden diferenciar programas según el tipo de relación educador-educando, según los medios utilizados, la metodología didáctica, el carácter individualizado o colectivizado de la enseñanza, etc.

E) Aplicando el criterio de la ubicación: Se pueden diferenciar programas estables, itinerantes, ubicados en edificios de uso exclusivamente educativo o destinados a otros usos, etc.

F) Aplicando el criterio temporal: Se pueden diferenciar programas en función de su duración, intensidad, mayor o menor flexibilidad horaria, continuidad, etc.

G) Aplicando el criterio económico: Se puede diferenciar entre programas autofinanciados, financiados por entidades públicas o privadas, con un sistema de financiación mixta.

H) Aplicando el criterio institucional: Se puede distinguir entre programas públicos (estatales, regionales, municipales, internacionales...), privados, mixtos.

I) Aplicando el criterio del grado de institucionalización o formalización: Se puede diferenciar entre programas muy institucionalizados (con profusión de normativa, burocratización, estructura organizativa...), semiinstitucionalizados o poco o nada institucionalizados. 
derse también a criterios distintos, por ejemplo, a las funciones y los destinatarios, lo cual nos permitiría destacar los tipos de actividades o programas educativos más relevantes cuantitativamente en función de los usuarios, por citar un ejemplo.

A. COLOM, J. SARRAMONA y G. VÁZQUEZ (1998) se decandan principalmente en su reciente obra por una clasificación de carácter funcional-temático, destacando los siguientes ámbitos:

- alfabetización

- formación laboral

- ocio y tiempo libre

- educación para el consumo

- educación para la salud

- educación urbana

- educación ambiental y conservación del patrimonio

- animación sociocultural

Finalmente, mencionaremos a P. CARIOLA (1991) quien clasifica diez ámbitos en los programas de educación no formal según sus finalidades o funciones, vinculadas también en algunos casos a determinadas áreas temáticas:

1. Equivalencias de educación básica, niveles superiores de educación general y especializaciones.

2. Educación ligada al empleo: a) Preparatoria al empleo, en empresas o por cuenta propia; b) organizada por las empresas para el personal que ba de trabajar con nuevas tecnologías o en nuevos empleos y c) actualización y reciclaje profesional.

3. Acciones de desarrollo educativo: interacción social, arte, cultura y recreación.

4. Enriquecimiento cultural de la calidad de vida, individual y familiar: relaciones intrafamiliares, desarrollo infantil, tercera edad, uso del tiempo libre.

5. Educación para la salud.

6. Educación para el medio ambiente y otros temas globales.

7. Programas de animación sociocultural.

8. Educación cívica.

9. Programas de desarrollo económico integral.

10.Educación anticipatoria para el cambio.

Por último, debemos hacer mención de toda la corriente de origen norteamericano (COOMBS, LA BELLE, etc.), extendida por los países de Latinoamérica y, en general, países en vías de desarrollo, que atribuyen a las instancias de ENF una finalidad fundamentalmente de "Concienciación" de los destinatarios de sus programas (generalmente sectores de población desfavorecidos desde el punto de vista social, económico y cultural), respecto de su propia situación personal y colectiva, así como de una mejor comprensión de los factores responsables de tal situación, lo cual llevará a una mejora de la autoconfianza y de las propias habili- 
dades que, junto al deseo de cambio, hará posible una mejora global de su situación (P. ELLIS, 1994, pp. 43).

En conclusión, pues, podemos percatarnos, como ya advertíamos al comienzo del artículo, de la amplia variedad de contextos sociales, económicos y culturales en los que se desarrolla la ENF y, en consecuencia, de la amplitud de finalidades, objetivos y funciones que puede asumir en cada uno de ellos. No obstante, en la actualidad, puede observarse, como apunta J. TRILLA (1993; pp. 32-33), una "polarización" hacia ciertos tipos de cometidos educativos, entre los que señala, "la alfabetización de adultos, la formación, reciclaje y promoción profesional, la extensión cultural, la educación para el tiempo libre y animación sociocultural, la educación

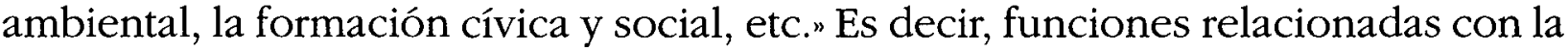
educación permanente y con dimensiones del proceso educativo olvidadas o deficientemente asumidas por la institución escolar. Asimismo, señala el mismo autor, la ENF cubre, a menudo, necesidades educativas particulares, inmediatas, autóctonas u ocasionales, que la educación formal, por su mayor rigidez estructural, no puede cubrir con tanta facilidad.

3. El CRECIMIENTO DE LAS NECESIDADES DE APRENDIZAJE Y LA EMERGENCIA DE NUEVOS ÁMBITOS DE EDUCACIÓN NO FORMAL. BASES PARA UNA PROPUESTA TAXONÓMICA

Todos los seres humanos, considerados tanto individual como colectivamente, experimentan desde su nacimiento y a lo largo de toda su vida constantes y diversas necesidades de aprendizaje, cuya forma, contenido y utilidad van evolucionando. I. W. BOTKIN y otros (1979) hacían una distinción entre dos grandes tipos de necesidades de aprendizaje humano: el aprendizaje de "mantenimiento", que capacitaría a los individuos para funcionar con eficacia en el sistema social establecido y el aprendizaje einnovador" que les capacitaría para anticiparse y adaptarse oportunamente a cambios importantes en el mundo que les rodea. Ambos son igualmente necesarios y, por tanto, deben tenerse en cuenta en la provisión de una oferta educativa adecuada.

En el primer informe de Ph. H. COOMBS (1968, trad. esp. 1971) se hacía hincapié en el aumento de necesidades de aprendizaje de la población mundial a partir de la Segunda Guerra Mundial y la incapacidad de los diferentes países para satisfacerlas con los medios y recursos habituales, en especial se señalaba como causas la rigidez de programas y contenidos de la educación formal, así como la desdichada costumbre de trasplantar miméticamente tales modelos educativos, propios de países desarrollados, en países en vías de desarrollo. Entre los factores causantes del aumento de la demanda educativa se apuntaban principalmente las crecientes aspiraciones educativas de las familias (tanto de padres como de hijos), el deseo de los poderes políticos de aumentar las tasas de escolarización y la explosión demográfica que actuaría como "multiplicador cuantitativo de la demanda social. 
En su segundo informe, $\mathrm{Ph}$. H. COOMBS (1985) reconocía que las necesidades de aprendizaje de individuos y colectividades "son diversas y mutables por naturaleza", idea en la que ha insistido el último Informe de la Unesco (J. DELORS, 1996) al afirmar que "la educación a lo largo de la vida tiene una dimensión pluridimensional", pero además, como se afirmaba en la Declaración Mundial sobre Educación para Todos (1990), la naturaleza y maneras de satisfacer dichas necesidades de aprendizaje "varían según cada país y cada cultura y cambian inevitablemente con el transcurso del tiempon. Por tanto, no admiten una medición matemática precisa, aunque se pueden destacar una serie de "factores" que las definen y condicionan, de entre los que Philip H. Coombs destaca:

- El crecimiento demográfico y los fenómenos migratorios

- La urbanización

- Los avances científicos y tecnológicos

- Los cambios sociales y económicos

- Los planes de desarrollo nacional y la progresiva interdependencia mundial.

Dichos factores estan íntimamente vinculados al desarrollo y a los cambios consiguientes en el orden económico, social, cultural, tecnológico, etc. que experimentan las sociedades en las cuales están inmersos los individuos y, aunque Philip Coombs advierte, por una parte, que tales factores son interdependientes y, por otra, que no afectan del mismo modo a todas las sociedades, realiza un análisis pormenorizado de los mismos que le permite extraer algunas conclusiones significativas. Por ejemplo, afirma que las presiones de crecimiento demográfico en los países en vías de desarrollo tienen como consecuencia un aumento del número de "aprendices" potenciales y, por tanto, de la demanda popular de educación básica a la que difícilmente pueden hacer frente los sistemas educativos formales. En los países desarrollados, en cambio, el factor demográfico no tiene la misma relevancia puesto que la tasa de crecimiento de la población se ha estabilizado y en algunos casos ha descendido, sin embargo se sigue experimentando un considerable y continuado incremento de las necesidades globales de aprendizaje debido a otros factores, como la introducción de nuevas tecnologías, modificaciones en el mercado de trabajo, mayor movilidad en el empleo, mayor incorporación de la mujer en el mundo laboral, aumento del tiempo de ocio, etc. Otro factor de gran importancia apuntado por dicho autor es el de los fenómenos migratorios impulsados por la pobreza o la búsqueda de mayor bienestar, cuyos resultados se traducen generalmente en el crecimiento de los asentamientos urbanos de grandes masas de población, generalmente de los países en vías de desarrollo hacia países desarrollados o, dentro del mismo país, desde zonas rurales a zonas urbanas. Respecto a él, afirma Coombs que todo este "trasvase" de población tiene unas consecuencias educativas de gran alcance, puesto que estas personas acusan inmediatamente un sinnúmero de nuevas necesidades educativas derivadas del hecho que han de adaptarse a vivir en un medio que les es desconocido y, así, han de aprender, desde una lengua diferente, tal vez a leer y escribir la propia, las técnicas de un 
nuevo trabajo, la manera de utilizar el transporte público, los servicios sanitarios, los procedimientos para rellenar los formularios oficiales, etc. La parte de esta población que no logra integrarse en la vida social y económica urbana forma grandes bolsas de marginación dando un aire rural degradado a extensas zonas periféricas de las ciudades. Estas migraciones masivas hacia zonas urbanas tienen también consecuencias sobre las necesidades de aprendizaje de la población rural. Se podría suponer que, al decrecer la población en las zonas rurales, se iría suavizando la situación de agobio por la mayor disponibilidad de tierras, sanidad, escuelas, etc. Sin embargo, paradójicamente no es así. Por una parte, porque las tasas de natalidad en las zonas rurales siguen siendo mucho más altas -por lo menos en lo que respecta a los países en vías de desarrollo- $y$, por otra, porque el abandono "oficial" y las carencias de infraestructura de todo tipo se hacen mucho más marcadas en estas zonas despobladas y, por tanto, las posibilidades de desarrollo y las condiciones de vida, más difíciles. En las zonas rurales de países en vías de desarrollo, así como en las zonas urbanas marginales o degradadas, las necesidades de aprendizaje van estrechamente ligadas a las necesidades básicas de supervivencia (sanidad, higiene, nutrición, mejora de la producción agrícola, planificación familiar, inserción laboral,...), pero también a la necesidad de asumir las actitudes, compromisos y comportamientos necesarios para salir de la situación de degradación.

Es interesante, en este punto, mencionar la publicación anterior de $\mathrm{Ph} . \mathrm{H}$. COOMBS, R. C. PROSSER y M. AHMED (1973 a) en la que elaboraron una lista de necesidades de aprendizaje específicas de los niños y jóvenes de zonas rurales que incluía los aprendizajes básicos funcionales, una visión científica y una comprensión elemental de los procesos naturales en un área concreta y el conocimiento práctico y habilidad para ganarse la vida, pero además, el fomento de actitudes positivas hacia la cooperación, al trabajo y a la educación permanente así como los conocimientos prácticos y habilidades necesarias para la participación ciudadana ${ }^{6}$.

Respecto a las necesidades de aprendizaje en zonas rurales de países desarrollados, aunque sus condiciones de vida son mejores y su infraestructura está más

${ }^{6}$ Reproducimos, por su interés, la cita textual de la obra a la que nos referimos:

"(a) Positive attitudes, toward co-operation with and help to one's family and fellow men, toward work and community and national development, and not least of all toward continued learning and toward the development of ethical values. Such attitudes should find concrete expression in one's daily behavior -in the family and the community, at work and in all learning environments.

(b) Functional literacy and numeracy, sufficient (i) to read with comprehension a national newspaper or magazine, useful agricultural, health, and other "how-to-do-it" bulletins, or manufacturers' instruction sheets; (ii) to write a legible letter to, for example, a friend or to a government bureau requesting information; and (iii) to handle important common computations such as measurement of land and buildings, calculation of agricultural input costs and revenues, interest charges on credit and rental rates on land.

(c) A scientific outlook and an elementary understanding of the processes of nature in the particular area, as they pertain, for example, to health and sanitation, to raising crops and animals, to nutrition, food storage and preparation and to the environment and its protection.

(d) Functional knowledge and skills for raising a family and operating a bousebold, including the essential elements of protecting family health, family planning where appropriate, good child care, nutri- 
desarrollada, se advierte que la población sigue necesitando una pericia ocupacional diferente y más amplia y una capacidad familiar y comunitaria algo distinta debido a su mayor necesidad de ser autodependiente en alto grado en muchos aspectos de la vida y de compenetrarse con su entorno natural. Para satisfacer estas necesidades específicas puede ser útil una amplia gama de actividades educativas no formales.

Pero como hemos advertido anteriormente, el generador más importante de nuevas necesidades de aprendizaje humano es, sin lugar a dudas, el desarrollo mismo: desarrollo científico, tecnológico, económico, social, político y cultural. Ello es la causa de que en los países industrializados, con tasas de escolarización formal muy elevadas y poblaciones estabilizadas, las necesidades de aprendizaje no estén relativamente estacionarias. Por el contrario, fruto del desarrollo económico, científico y tecnológico se están creando continuas necesidades de reciclaje y perfeccionamiento profesional, de actualización de conocimientos de todo tipo, de manejo de nuevas tecnologías, de aprendizaje de técnicas tipo "hágalo usted mismo" (bricolage, fontanería..) debido a los altos costes de reparación, de conservación y mejora del medio ambiente, de aprendizaje de estrategias para hacer frente a la avalancha consumista y publicitaria, etc. Los cambios políticos producidos en muchos países han generado asimismo nuevas necesidades de aprendizaje para adaptarse a las nuevas situaciones y valores (ideales democráticos, pacifistas...). Lo mismo podríamos decir de los cambios sociales y/o culturales que han modificado muchos de los roles tradicionales, creando continuas necesidades de adaptación personal y colectiva. A modo de ejemplos, podríamos citar la progresiva incorporación de la mujer a la vida pública y el cambio de los roles familiares y sociales entre sexos; otro cambio muy importante a destacar sería el progresivo envejecimiento de la población debido al aumento de la esperanza y calidad de vida, que ha hecho aumentar las demandas educativas de los mayores. En el otro extremo, deberíamos mencionar la mayor preocupación por la educación infantil desde una edad muy temprana, lo que ha generado interés por parte de padres y madres de recibir la formación adecuada para atender a sus hijos convenientemente desde su nacimiento. Otro aspecto que cabría resaltar es el de la mayor preocupación por la calidad de vida, por el aspecto personal, y, consiguientemente, por los

tion and sanitation; cultural activities and recreation; care of the injured and sick; intelligent shopping and use of money; making clothes and other consumption goods, house repairs and environmental improvements; growing and preserving food for family consumption.

(e) Functional knowledge and skills for earning a living, including not only the skills required for a particular local occupation, but also a knowledge of a variety of locally useful common skills for agriculture and nonfarm use.

(f) Functional knowledge and skills for civic participation, including some knowledge of national and local history and ideology, and understanding of one's society; awareness of government structure and functions; taxes and public expenditures; available social services; rights and obligations of individual citizens; principles, aims and functioning of cooperatives and of local voluntary associations". 
temas relativos a la salud, la nutrición, la contaminación ambiental, el ejercicio físico, etc. Finalmente, podríamos señalar una mayor preocupación social por las necesidades educativas de los discapacitados, enfermos, marginados de todo tipo, etc. a los que se ha prestado mayor atención en los últimos años en los países desarrollados, aunque el problema reviste características dramáticas en el llamado Tercer mundo, así como por el fomento de valores de solidaridad y cooperación.

En conjunto, Philip Coombs concluye afirmando que el explosivo crecimiento de necesidades de aprendizaje por parte de la población que se viene dando a partir de la segunda guerra mundial, tanto en países desarrollados como en vías de desarrollo, está ligado a toda una serie de factores interrelacionados de cambio y desarrollo a distintos niveles y que todos los indicadores apuntan a que, lejos de desaparecer o disminuir, van a seguir en plena vigencia, con lo que las demandas educativas seguiran creciendo en las próximas décadas. Para hacer frente a estas demandas, es evidente que la oferta va a seguir aumentando y diversificándose en todos los sectores educativos -lo que plantea, por razones obvias, una perentoria necesidad de coordinación entre todos ellos-, aunque, por sus características específicas de mayor inmediatez, flexibilidad y adaptabilidad a contextos, circunstancias y destinatarios concretos, el sector educativo no formal adquirirá una especial importancia en el futuro, siendo precisamente su capacidad de respuesta ante las exigencias educativas del desarrollo de las sociedades lo que marcará su evolución y expansión.

Partiendo, pues, de los postulados de Philip H. Coombs, fundamentaremos nuestra propuesta taxonómica relativa a los ámbitos de la educación no formal en el análisis de las necesidades de aprendizaje de los diversos sectores de la población, en función de las tendencias y/o consecuencias generales del desarrollo en los distintos campos, económico, político, social, cultural, científico y tecnológico. Con ello pretendemos cumplimentar, a la vez, una función descriptiva de la realidad educativa no formal en un momento histórico dado y una función crítica y prospectiva que nos permita vislumbrar sus posibilidades de evolución y expansión futura, detectar sus insuficiencias, prever sus necesidades, plantear propuestas de mejora... y, en definitiva, tratar de anticiparnos desde el campo de la Pedagogía y en un marco de cooperación multidisciplinar y multisectorial, a las exigencias y los retos de la educación de los individuos y de los pueblos.

Hemos de advertir, sin embargo, que somos conscientes de que, al fragmentar el proceso de desarrollo de las sociedades en distintas áreas (económica, política, sociocultural y científico-tecnológica) caemos en las mismas contradicciones que señalábamos al analizar otros criterios taxonómicos (funcionales, institucionales, contextuales...) utilizados en la educación no formal. Efectivamente, sabemos que la evolución de los individuos y los pueblos en las distintas áreas apuntadas es un proceso profundamente interrelacionado que, por tanto, no puede abordarse desde posiciones rígidas o sectarias. Del mismo modo, no olvidamos que las necesidades educativas que esa evolución genera son fruto de la confluencia de distintas facetas del desarrollo, aunque optemos por vincularlas preferentemente a una 
de ellas en concreto. Y es que, al final, parece que no podemos sustraernos a la necesidad metodológica de marcar algunas fronteras al proceso global de desarrollo a efectos de acotar y tratar de ordenar un sector tan vasto y heterogéneo como la educación no formal que, precisamente, surge y se constituye como la respuesta educativa organizada de la sociedad civil frente a las necesidades formativas que genera continuamente este proceso de desarrollo en sus múltiples facetas.

Así pues, iniciaremos nuestra propuesta taxonómica relativa a los ámbitos de la educación no formal estableciendo una primera diferenciación entre:

1. ENF que responde a necesidades educativas orientadas al desarrollo económico.

2. ENF que responde a necesidades educativas orientadas al desarrollo social $y$ cultural.

3. ENF que responde a necesidades educativas orientadas al desarrollo politico.

4. ENF que responde a necesidades educativas orientadas al desarrollo científico y tecnológico.

Analizaremos, a continuación, cada uno de estos grandes ámbitos, tomando como punto de partida la distinción de distintos componentes o aspectos vinculados a cada faceta del desarrollo, económica, sociocultural, política y científico tecnológica (véanse en las páginas siguientes las figuras 1, 2, 3 y 4).

Seguidamente, estableceremos algunas de las principales tendencias de evolución dentro de cada uno de dichos componentes o subámbitos, las cuales, a su vez, dan lugar a la emergencia de nuevas necesidades formativas entre la población a cuya satisfacción se orientan los programas de educación no formal, de los que citamos algunos ejemplos ilustrativos:

1. EDUCACIÓN NO FORMAL QUE RESPONDE A NECESIDADES EDUCATIVAS ORIENTADAS AL DESARROLLO ECONÓMICO

1.1. Mundo LABORAL

1.1.1. Algunas tendencias del desarrollo económico en relación al mundo laboral

$\Rightarrow$ Aparición de nuevas profesiones y desaparición progresiva de otras.

$\Rightarrow$ Mayor movilidad laboral.

$\Rightarrow$ Mayor exigencia de competencia y/o especialización en el trabajo.

$\Rightarrow$ Ampliación continua de conocimientos y habilidades.

$\Rightarrow$ Creciente desajuste entre formación inicial para un puesto concreto y el empleo dentro del mismo puesto.

$\Rightarrow$ Mayor sofisticación de los sistemas de gestión e información en las empresas.

$\Rightarrow$ Mayor internacionalización de las empresas. 
FIgURA 1

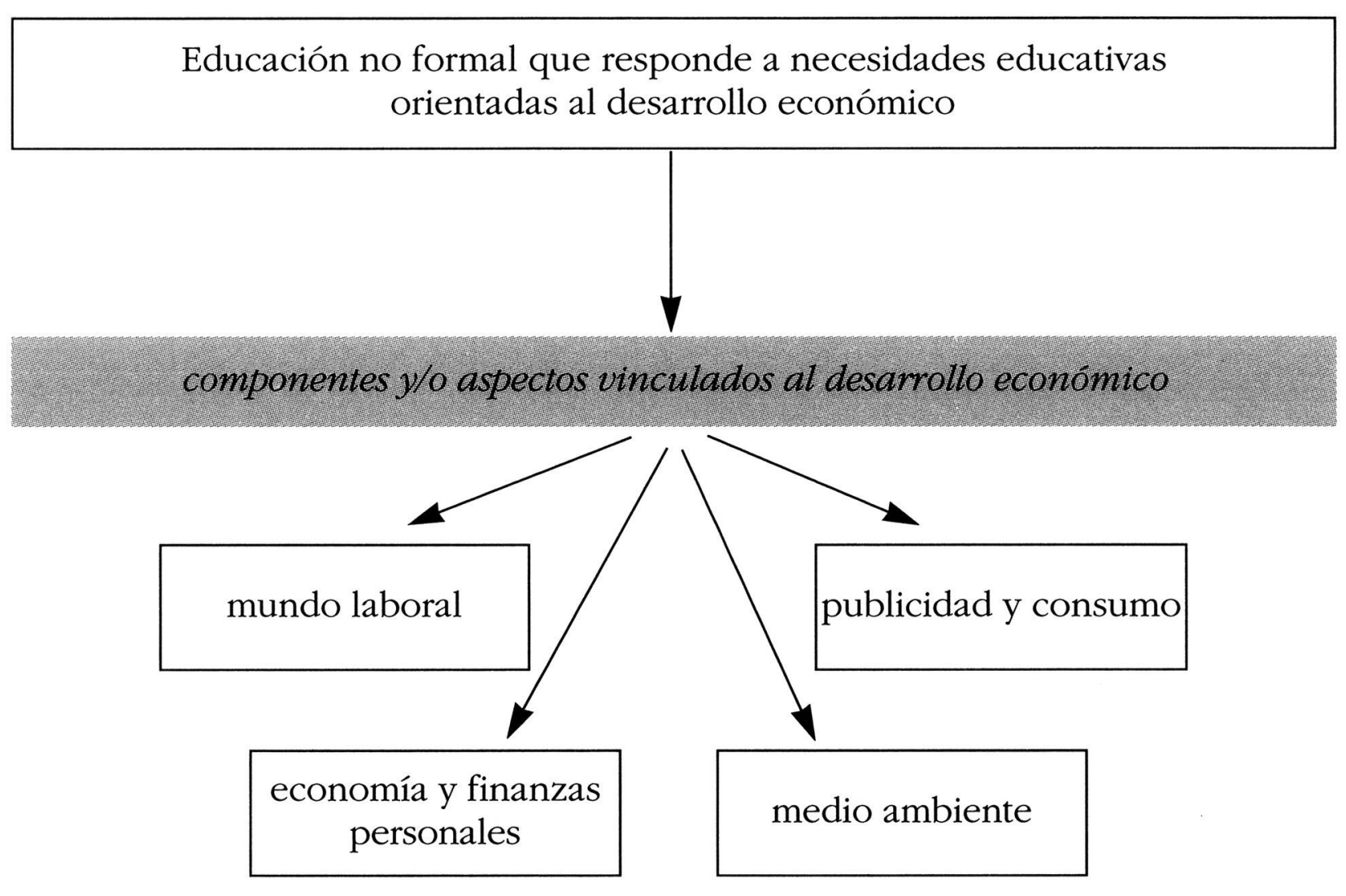

FiguRA 2

Educación no formal que responde a necesidades educativas orientadas al desarrollo social y cultural

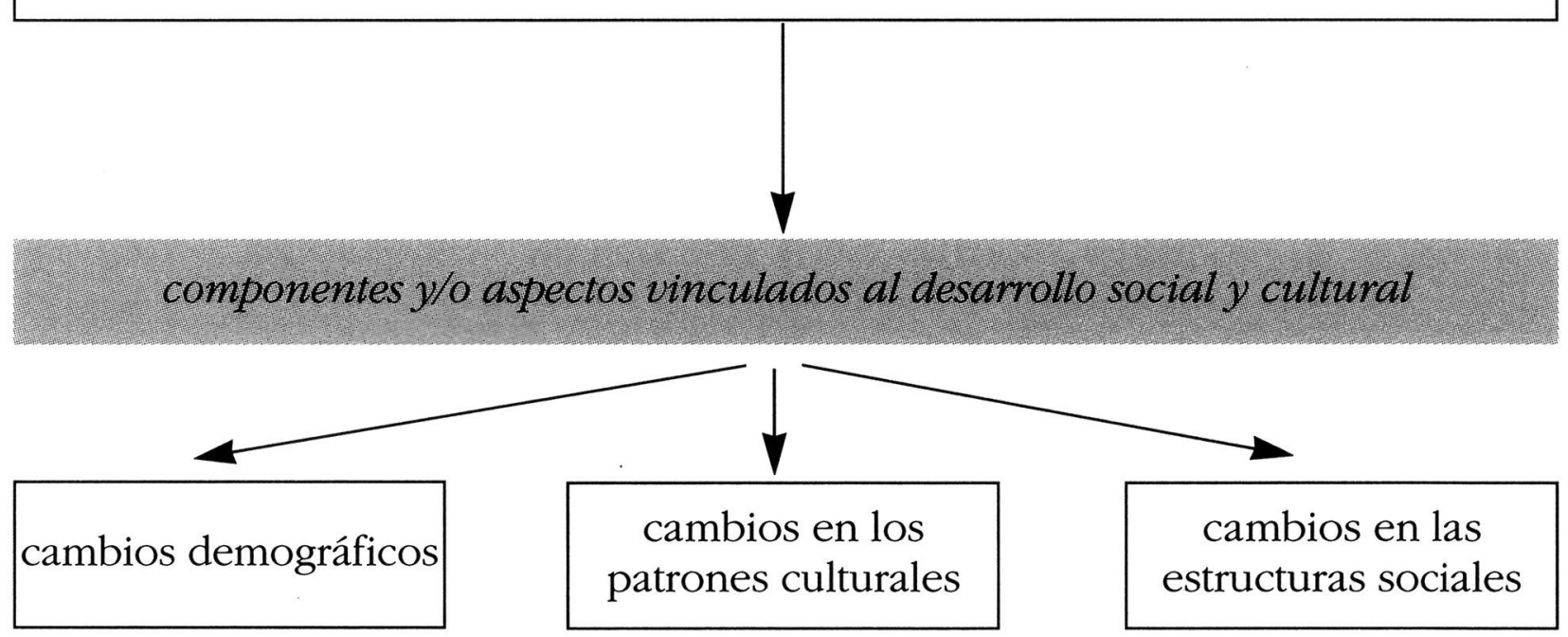

(C) Ediciones Universidad de Salamanca 
FIGURA 3

Educación no formal que responde a necesidades educativas orientadas al desarrollo político

FIGURA 4

componentes y/o aspectos vinculados al desarrollo politico

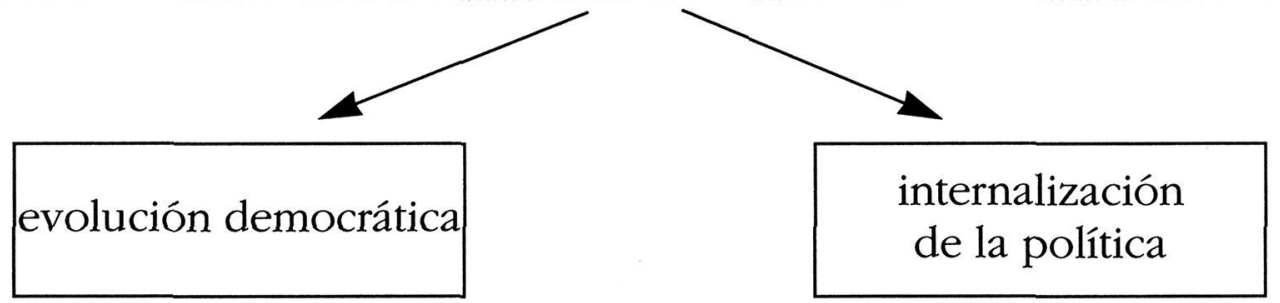

Educación no formal que responde a necesidades educativas orientadas al desarrollo científico-tecnológico

componentes y/o aspectos vinculados al desarrollo científico-tecnológico

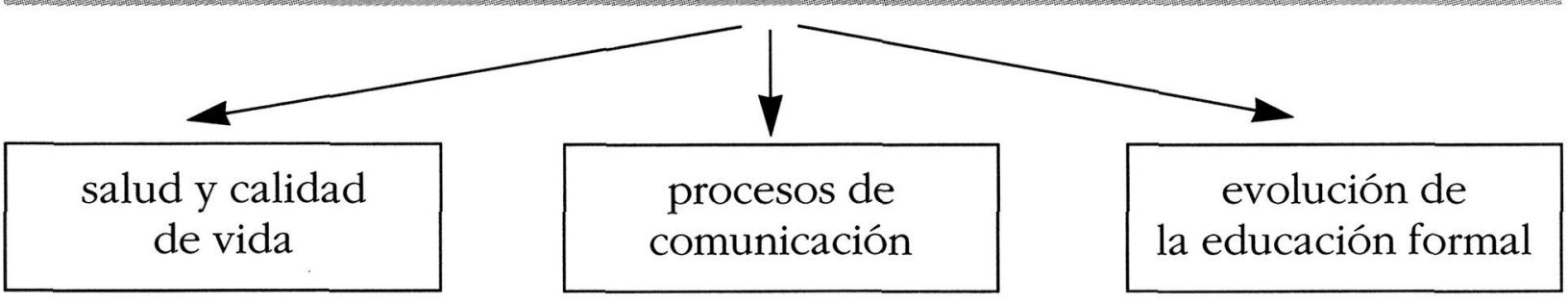


$\Rightarrow$ Cronificación del problema del paro.

$\Rightarrow$ Mayor trabajo en equipo.

$\Rightarrow$ Incorporación de nuevos sectores de población al mundo laboral.

$\Rightarrow$ Mayor complejidad administrativo-burocrática en torno al mundo laboral.

$\Rightarrow$ Crecimiento del sector público.

1.1.2. Ejemplos de programas de ENF que atienden necesidades formativas específicas relacionadas con el mundo laboral

* Recualificación profesional de personas que no pueden subsistir con sus antiguos trabajos y deben adaptarse a nuevas profesiones (por ejemplo, gentes que proceden del sector primario o secundario en recesión).

* Formación o reciclaje ocupacional de jóvenes y personas en situación de paro.

* Formación ocupacional de sectores de población escasamente cualificados y/o en situación de marginación social (talleresescuela, etc.).

* Información y orientación para desenvolverse dentro del mundo laboral-administrativo y capacitación para buscar soluciones a las diversas situaciones y problemas que puedan plantearse (especialmente para jóvenes que buscan su primer empleo, personas en paro, sectores de población que desean incorporarse al mundo laboral...).

* Formación para acceder a puestos de trabajo en el sector público (preparación de oposiciones, etc).

* Formación sindical, sobre legislación laboral, etc.

* Perfeccionamiento laboral para trabajadores en activo para actualización de conocimientos y destrezas, mayor especialización, promoción a puestos de mayor responsabilidad, etc.

* Formación sobre higiene y salud laboral.

* Formación sobre nuevos sistemas de comunicación e información (nuevas tecnologías).

* Formación sobre nuevas técnicas de organización y gestión empresarial (empresarios, trabajadores autónomos...).

* Aprendizaje de idiomas extranjeros.

* Aprendizaje de idiomas del país receptor para trabajadores inmigrantes.

* Aprendizaje de técnicas de trabajo en equipo, gestión cooperativa, etc.

* Formación fiscal y financiera. 
$M^{\mathbf{a}}$. INMACULADA PASTOR HOMS

ÁMBITOS DE INTERVENCIÓN EN EDUCACIÓN NO FORMAL. UNA PROPUESTA TAXONÓMICA

1.2. ECONOMÍA Y FINANZAS PERSONALES

1.2.1. Algunas tendencias del desarrollo económico en relación a la economia y las finanzas personales

$\Rightarrow$ Mayor dependencia de los individuos respecto a las entidades financieras.

$\Rightarrow$ Modificación de los cánones tradicionales de ahorro y rentabilización de los ingresos personales.

$\Rightarrow$ Mayor complejidad de la normativa fiscal

$\Rightarrow$ Internacionalización creciente de la economía.

1.2.2. Ejemplos de programas de ENF que atienden necesidades formativas relacionadas con la gestión de la economía y las finanzas personales

* Formación general sobre los principios básicos que rigen la actividad económica, así como comprensión del lenguaje especializado más comunmente utilizado.

* Información sobre el funcionamiento de las entidades financieras y orientación objetiva sobre los diversos tipos de productos que ofrecen.

* Formación/orientación para conseguir una mayor rentabilidad de los ingresos personales en base a las posibilidades reales existentes.

* Formación respecto a los nuevos medios tecnológicos de información financiero-económica.

* Formación sobre las normativas fiscales.

\subsection{Publicidad y CONSUmo}

1.3.1. Algunas tendencias del desarrollo económico en relación a la publicidad y el consumo

$\Rightarrow$ Incremento y sofisticación de las técnicas y medios publicitarios, observándose una clara tendencia a incidir en la esfera afectiva y emotiva de los destinatarios.

$\Rightarrow$ Crecimiento acelerado y mayor diversificación y especialización de la oferta de productos de consumo (destinada, a menudo, a grupos específicos: deportistas, ejecutivos, adolescentes, gourmets, etc.).

$\Rightarrow$ Incremento de la utilización de sustancias o materiales artificiales en la elaboración de productos de consumo (alimentos, ropa...) cuya inocuidad no ha sido rigurosamente probada.

$\Rightarrow$ Valoración de los parámetros cuantitativos más que los cualitativos en la elaboración de productos de consumo.

$\Rightarrow$ Incremento del coste de los servicios técnicos o de reparación de determinados productos. 
$\Rightarrow$ Complejidad y difícil comprensión de los mensajes de información al consumidor (utilización de símbolos, de terminología especializada...).

$\Rightarrow$ Incremento de hábitos irracionales de consumo en sectores cada vez más amplios de la población (niños y jóvenes, especialmente) que producen graves consecuencias a nivel personal (psicológicas, sanitarias, económicas...) y social (ecológicas, desigualdad, insolidaridad...).

1.3.2. Ejemplos de programas de ENF que atienden necesidades formativas específicas relacionadas con la publicidad y los bábitos consumistas

* Conocimiento general y suficiente de la legislación y normativas sobre publicidad y consumo (derechos y deberes de productores y consumidores, posibilidades asociativas de los consumidores, etc.).

* Conocimiento de las técnicas básicas utilizadas en las áreas de la publicidad y el márketing.

* Conocimiento del lenguaje especializado y la simbología específica utilizados en los mensajes de información al consumidor (etiquetaje, precios, facturas, recibos, etc.).

* Información clara y asequible sobre el correcto uso, así como capacitación para realizar pequeñas reparaciones caseras de determinados productos de consumo.

* Información objetiva y veraz de los riesgos que implica el consumo de determinados productos.

* Formación medioambiental relacionada con el consumo (información sobre productos y envoltorios contaminantes, desechables, reciclables..., sobre la eliminación de residuos, sobre el consumo de sustancias o materiales escasos o perjudiciales para el medio ambiente, etc.).

* Capacitación para dar una respuesta racional, autónoma y crítica ante la avalancha publicitario-consumista.

\subsection{MEDIO AMBIENTE}

1.4.1. Algunas tendencias del desarrollo económico en relación al medio ambiente

$\Rightarrow$ Incremento del deterioro y la contaminación en numerosas zonas naturales fruto del incontrolado crecimiento industrial, urbanístico, de la sobreexplotación de los recursos, del hacinamiento de residuos, de los incendios, etc.

$\Rightarrow$ Incremento del deterioro ambiental en zonas urbanas y suburbanas debido a la contaminación por actividades económicas (humos, ruidos, vertidos, basuras, luces, etc.). 
$\Rightarrow$ Abandono de zonas rurales con el consiguiente peligro de degradación.

$\Rightarrow$ Incremento entre la población en general de los hábitos generadores de contaminación (utilización masiva de vehículos privados, incremento del consumo, mayor generación de basuras, falta de respeto hacia los demás, etc).

$\Rightarrow$ Internacionalización de la problemática medioambiental

$\Rightarrow$ Incremento de los conocimientos científicos que permiten una mejor comprensión de los procesos medioambientales $\mathrm{y}$, consecuentemente, aumento del interés y la preocupación en algunos sectores de la población por la consecución de un modelo de desarrollo económico compatible con la conservación del medio ambiente.

1.4.2. Ejemplos de programas de ENF que atienden necesidades formativas relacionadas con la conservación y mejora del medio ambiente

* Conocimiento general del funcionamiento de los ecosistemas y de los peligros que entraña su alteración incontrolada por razones económicas.

* Conocimiento y respeto hacia los espacios naturales y espacios urbanos con valor ecológico existentes en la propia comunidad.

* Información/formación medioambiental en relación directa con la actividad laboral desempeñada (dirigida, por ejemplo, a agricultores, ganaderos, pescadores, transportistas, restauradores, industriales, hoteleros, arquitectos, etc.).

* Información/formación ambiental en relación directa con las actividades de ocio (excursiones; paseos por la ciudad; cuidado de animales domésticos; escuchar música; ver la televisión; utilización de lugares públicos como cines, discotecas, bares, piscinas...; utilización de medios de transporte, etc.

2. EDUCACIÓN NO FORMAL QUE RESPONDE A NECESIDADES EDUCATIVAS ORIENTADAS AL DESARROLLO SOCIAL Y CULTURAL

2.1. CAMBIOS DEMOGRÁFICOS

2.1.1. Algunas tendencias del desarrollo social y cultural en relación a los cambios demográficos

$\Rightarrow$ Mayor movilidad geográfica de la población: desde zonas rurales a zonas urbanas, desde países del Tercer Mundo a países desarrollados, etc.

$\Rightarrow$ Mayor contacto entre culturas distintas.

$\Rightarrow$ Abandono y degradación de zonas rurales o en recesión económica. 
$\Rightarrow$ Incremento de los problemas derivados del desarraigo sociocultural y de la pérdida del sentido de pertenencia (aparicición de zonas urbanas degradadas, marginación, violencia, etc.).

$\Rightarrow$ Envejecimiento de la población.

2.1.2. Ejemplos de programas de ENF que atienden necesidades educativas específicas relacionadas con los cambios demográficos:

* Conocimiento de idiomas.

* Conocimiento de patrones culturales distintos a los propios y adquisición de valores y actitudes de tolerancia y respeto a las diferencias étnicas y culturales: programas de educación multicultural dirigidos a la población en general o a grupos específicos, programas y campañas para la erradicación de actitudes racistas.

* Conocimiento de la cultura popular (artesanía, oficios, fiestas, literatura popular, tradiciones, comidas, etc.) como medio de favorecer el sentido de pertenencia y la reactivación económica.

* Desarrollo comunitario integral de zonas rurales o en recesión.

* Formación destinada específicamente a las personas mayores para ayudarles a mantener/ mejorar su calidad de vida (cuidado personal, alimentación, utilización de servicios, ...) y enriquecer su vida personal y social (acceso a la cultura, participación social, desarrollo de las capacidades artísticas, posibilidad de interrelaciones personales, etc.).

\subsection{CAMBIOS EN LAS ESTRUCTURAS SOCIALES}

2.2.1. Algunas tendencias del desarrollo social y cultural vinculado a los cambios en las estructuras sociales

$\Rightarrow$ Cambios en los roles tradicionales familiares: incorporación de la mujer al mundo sociolaboral; descenso del número de hijos; asunción por parte de la sociedad de determinadas funciones asistenciales, educativas..., tradicionalmente asumidas por la familia; cambios en las relaciones de convivencia de la pareja y entre padres e hijos, etc.

$\Rightarrow$ Mayor complejidad de las estructuras y la organización sociales (burocratización, incremento y sofisticación de los servicios, masificación, etc.).

$\Rightarrow$ Mayor permeabilidad de las estructuras sociales, lo cual genera un crecimiento de las expectativas educativas de los adultos y de los padres con respecto a sus hijos.

$\Rightarrow$ Persistencia de grandes desigualdades socio-económicas y culturales entre distintos sectores de la población. 
2.2.2. Ejemplos de programas de ENF que atienden necesidades educativas específicas relacionadas con los cambios en las estructuras sociales

* Formación básica y general suficiente de toda la población, especialmente de jóvenes y adultos que han tenido una escolarización deficiente, para subsistir en una sociedad cada vez más compleja (programas de alfabetización, alfabetización funcional, de "segunda oportunidad", etc.).

* Educación para la solidaridad.

* Información y capacitación para desenvolverse sin problemas en el medio urbano (programas sobre el funcionamiento y la utilización de los distintos servicios urbanos: medios de transporte, policia, bomberos, servicios de suministro de agua, gas, luz, recogida de basuras, etc.; educación vial; aprendizaje de conducción de vehículos; etc.

* Formación destinada a padres y a futuros padres: preparación para el embarazo y parto; lactancia; puericultura; estimulación precoz; evolución física, psicológica, social... de los hijos; comprensión y mejora de las relaciones entre padres e hijos prevención de problemas; etc.

* Formación para afrontar y/o mejorar las relaciones de pareja a todos los niveles.

\subsection{CAMBIOS EN LOS PATRONES CULTURALES}

2.3.1. Algunas tendencias del desarrollo social y cultural relacionado con los cambios en los patrones culturales

$\Rightarrow$ Mayor democratización cultural.

$\Rightarrow$ Expansión de la creencia en la "rentabilidad" de la inversión cultural (a nivel económico, de tiempo dedicado, etc.) e incremento de las ofertas culturales (cine, teatro, exposiciones, recitales, etc).

$\Rightarrow$ Tendencia a la uniformización y masificación de los modelos culturales, principalmente por la acción de los medios de comunicación de masas (especialmente la televisión)

$\Rightarrow$ Incremento del turismo.

$\Rightarrow$ Intensificación de la vida social.

$\Rightarrow$ Mayor igualdad entre sexos.

$\Rightarrow$ Mayor preocupación por la imagen y el aspecto físico.

$\Rightarrow$ Cambios en el uso y la valoración del tiempo libre:

- Mayor diferenciación y ruptura entre «tiempo dedicado al trabajo" y "tiempo libre".

- Por distintas razones (stress, alienación por trabajos rutinarios y mecánicos, menor consideración del trabajo como un fin en 
sí mismo...), mayor valoración y necesidad de aaprovechamiento" del tiempo libre.

- Tendencia al individualismo en el uso del tiempo libre.

- Mayor sentido lúdico y hedonístico en el uso del tiempo libre.

- Incremento de la población que dispone de más tiempo libre (jubilados, parados, trabajadores con reducción de jornada laboral, trabajo a tiempo parcial, trabajo de temporada...).

- Por diversas razones (laborales, sociales...), los niños, jóvenes y personas mayores comparten menos tiempo libre con sus familias. Surgen alternativas (grupos de iguales).

2.3.2. Ejemplos de programas de ENF que atienden necesidades formativas especificas relacionadas con el cambio de patrones culturales

* Conocimiento y comprensión del valor del patrimonio cultural (histórico, artístico, literario, arquitectónico, etc.), pasado y presente, de la sociedad: programas de educación patrimonial en museos, galerías de arte, teatros, auditorios, bibliotecas, monumentos, edificios singulares, turismo cultural, etc.

* Formación integrada para un uso más enriquecedor, creativo, diversificado y autónomo del tiempo libre y de ocio: programas de animación sociocultural y/o de educación para el ocio destinadas a grupos de niños, jóvenes, adultos y personas mayores desarrollados por clubs, asociaciones, residencias de mayores, instituciones cívicas, colegios, etc.

* Formación artístico-creativa y artesanal: cursos y talleres de pintura, cerámica, música, fotografía, teatro, punto, bordado, jardinería..., en instituciones diversas o a distancia.

* Formación físico-deportiva: cursos y clases diversas en gimnasios; polideportivos; a través de medios audiovisuales: televisión, video...; en colonias y campamentos de vacaciones; en clubs y asociaciones, etc.

* Formación gastronómica y culinaria: manuales, programas de televisión, cursillos de cocina, etc.

* Formación relacionada con el juego en ludotecas, en conmemoraciones festivas al aire libre, en clubs y asociaciones, etc.

* Formación moral-religiosa: catequesis de niños y adultos en las distintas confesiones religiosas.

* Promoción del hábito de la lectura en bibliotecas.

* Formación destinada a la erradicación de actitudes y comportamientos sexistas.

* Formación sobre distintas facetas del cuidado / mejora personal de la imagen y el aspecto físico: cursos de maquillaje, cosmética, adelgazamiento, etc. 
* Formación relacionada con la vida social y los usos y convencionalismos sociales: cursos sobre "como comportarse en la mesa", "como preparar una fiesta", decoración, arreglos florales, etc.

* Información/ formación respecto a los medios de comunicación de masas (prensa, radio, televisión, redes informáticas) y capacitación para afrontar críticamente y autónomamente la "avalancha" informativa.

* Fomento del asociacionismo y formación relativa a la creación y gestión de asociaciones.

3. EDUCACIÓN NO FORMAL QUE RESPONDE A NECESIDADES EDUCATIVAS ORIENTADAS AL DESARROLLO POLÍTICO

\subsection{EVOLUCIÓN DEMOCRÁTICA}

3.1.1. Algunas tendencias del desarrollo politico relacionado con la evolución democrática

$\Rightarrow$ Crecimiento cuantitativo de los regímenes políticos de carácter democrático.

$\Rightarrow$ Aceptación generalizada en nuestra sociedad de los principios y valores democráticos en la vida política.

$\Rightarrow$ Desconocimiento por parte de la población en general de las instituciones políticas y de sus mecanismos de funcionamiento.

$\Rightarrow$ Poca participación en la vida política de la mayoría de la población (desconocimiento de los procedimientos de participación, desinterés, etc.).

$\Rightarrow$ Desconocimiento general a nivel legislativo (leyes y normas básicas que regulan la vida pública).

3.1.2. Ejemplos de programas de ENF que atienden necesidades formativas específicas relacionadas con la evolución democrática

* Difusión de los valores y actitudes democráticos en la vida política: respeto a las ideas, participación, responsabilidad, honestidad, solidaridad, etc.

* Conocimiento de las instituciones políticas (ejecutivas, legislativas y judiciales) y de sus mecanismos de funcionamiento: programas educativos en ayuntamientos, parlamentos, gobiernos, juzgados, etc.

* Formación respecto a los procedimientos de participación ciudadana en la vida política: conocimiento del funcionamiento de los partidos políticos y de otras entidades de participación ciudadana; conocimiento sobre los procesos electorales, etc.

* Formación general de carácter político-legislativa: conocimientos básico de las teorías o ideologías políticas; conocimiento del significado de los progrmas electorales; capacitación para comprender y analizar crítica y autónomamente la actividad política; 
conocimiento de las leyes fundamentales que rigen la vida pública (constitución, estatutos de autonomía, leyes más importantes, etc.).

\subsection{INTERNACIONALIZACIÓN DE LA POLÍTICA}

3.2.1. Algunas tendencias del desarrollo politico relacionado con la internacionalización de la vida política

$\Rightarrow$ Creciente interdependencia a nivel mundial de la actividad política y económica.

$\Rightarrow$ Proliferación de entidades y organizaciones supranacionales.

$\Rightarrow$ Proceso de unificación europea.

$\Rightarrow$ Incremento de las desigualdades entre países desarrollados y países del Tercer mundo.

$\Rightarrow$ Persistencia de las respuestas violentas para resolver los conflictos políticos (terrorismo, guerra...)

3.2.2. Ejemplos de programas de ENF que atienden necesidades formativas específicas relacionadas con la internacionalización de la vida politica

* Conocimiento de las organizaciones y entidades supranacionales más importantes y de las actividades que desarrollan.

* Fomento de la conciencia europea o europeísta: Programas y campañas relacionadas con la llamada "dimensión europea de la educación".

* Educación para la paz.

* Educación para la solidaridad internacional: Divulgación de la problemática de los países del Tercer mundo y campañas de concienciación de la población llevadas a cabo por ONGs, organizaciones religiosas, ciudadanas, etc.

4. EDUCACIÓN NO FORMAL QUE RESPONDE A NECESIDADES EDUCATIVAS ORIENTADAS AL DESARROLLO CIENTÍFICO Y TECNOLÓGICO

\subsection{SALUD Y CALIDAD DE VIDA}

4.1.1. Algunas tendencias del desarrollo científico-tecnológico relacionado con la salud y la calidad de vida

$\Rightarrow$ Mejoría progresiva de los niveles de salud y calidad de vida de la población en general debido a las mayores posibilidades de prevención y curación de enfermedades.

$\Rightarrow$ Aumento de la población con enfermedades o minusvalías crónicas debido al incremento de conocimientos y recursos que permiten alargar la esperanza y calidad de vida de personas con enfermedades o dolencias incurables.

$\Rightarrow$ Aumento de enfermedades relacionadas con hábitos y modos de vida actuales (sedentarismo, competitividad, tensión, prisas, adicciones, etc.). 
$\Rightarrow$ Mayor concienciación de la importancia de la prevención en los temas de salud.

4.1.2. Ejemplos de programas de ENF que atienden necesidades formativas relacionadas con la salud y la calidad de vida

* Formación para la prevención y/o detección precoz de enfermedades (nutrición, higiene, adicciones, hábitos de vida, riesgos de contagio, autocontroles, etc.).

* Formación sobre salud infantil (enfermedades más frecuentes de los niños y su tratamiento, alimentación e higiene infantiles, etc.).

* Formación para mejorar la calidad de vida de los enfermos crónicos (enfermos mentales, diabéticos, enfermos de Sida, personas con minusvalías y discapacidades diversas...) y de sus familiares y amigos.

* Formación para la prevención y/o actuación en caso de accidente (en la utilización de medios de transporte, en el hogar, en lugares al aire libre, etc.).

* Conocimientos de socorrismo y primeros auxilios.

* Formación sexual.

\subsection{PROCESOS DE COMUNICACIÓN}

4.2.1. Algunas tendencias del desarrollo científico-tecnológico en relación a los procesos de comunicación

$\Rightarrow$ Rápido incremento y diversificación de la tecnología relacionada con la comunicación humana (mass media, redes informáticas, telefonía...)

$\Rightarrow$ Aumento de la necesidad de información/comunicación para el normal desenvolvimiento en las distintas situaciones de la vida actual.

4.2.2. Ejemplos de programas de ENF que atienden necesidades formativas específicas relacionadas con los procesos de comunicación

* Conocimiento de las nuevas tecnologías relacionadas con los procesos de comunicación en la vida cotidiana.

* Formación en relación a los medios de comunicación (prensa, televisión...).

4.3. EVOLUCIÓN DE LA EDUCACIÓN FORMAL

4.3.1. Algunas tendencias del desarrollo científico-tecnológico en relación a la evolución de la educación formal

$\Rightarrow$ Incremento de los conocimientos y destrezas considerados necesarios en la enseñanza formal básica.

$\Rightarrow$ Progresiva ampliación y masificación del sistema educativo formal. 
$\Rightarrow$ Insuficiencia de los recursos destinados al sistema educativo formal para hacer frente a la demanda cuantitativa y cualitativa.

$\Rightarrow$ Aumento de los índices de fracaso y abandono en el sistema educativo formal.

$\Rightarrow$ Rápido desfase de la formación recibida en la enseñanza formal por el continuo avance del conocimiento.

\subsubsection{Ejemplos de programas de ENF que atienden necesidades formativas} específicas relacionadas con la evolución de la educación formal

* Técnicas de estudio.

* Orientación escolar y vocacional.

* Refuerzo escolar: clases particulares, clases de recuperación en academias o en escuelas fuera del horario lectivo o durante los períodos vacacionales, etc.

* Preparación para las pruebas de acceso a los distintos niveles o titulaciones del sistema educativo formal: acceso a la universidad mayores de 25 años, graduado escolar o de educación secundaria.

* Reeducación de problemáticas específicas relacionadas con el aprendizaje escolar (logopedia...).

* Reciclaje y actualización de conocimientos científicos y tecnológicos en distintas areas para la población en general.

\section{BiBLIOGRAFÍA}

AA.VV. (1990): La ciutat educadora. Ajuntament de Barcelona. I Congrés Internacional de Ciutats Educadores.

- (1991): La educación no formal, una prioridad de futuro. Madrid: Fundación Santillana.

AHMED, M (1983): "Lo no formal y las cuestiones críticas de la educación", en Perspectivas, vol. XIII, no 1, 1983, págs. 35-44.

ANDERSON, C. A. (1972): "Reflexions sur la planification de l'enseignement extra-scolaire", en AA.VV.: La planification de l'éducation extra-scolaire en vue du développement París: UNESCO, págs. 35-47.

- (1976): "Factores impulsores y restrictores", en BREMBECK, C. S.; THOMPSON, T. J.: Nuevas estrategias para el Desarrollo Educativo. Investigación Intercultural de alternativas no formales. Buenos Aires: Guadalupe, págs. 47-67.

BACQUELAINE, M. (et al.) (1989): "Problemática de la educación no formal", en Radio y educación de adultos, $\mathrm{n}^{\mathrm{O}} 10$, págs. 5-11.

BHOLA, H. S. (1983): "La educación no formal en perspectiva”, en Perspectivas, vol XIII, no 1 , págs. 45-54.

BOCK, J. C. (1976): "The institutionalization of Non-Formal Education: A response to Conflicting Needs", en Comparative Education Review, vol. 20, nº 3, págs. 46-67. 
- y PAPAGIANNIS, G. J. (comps.) (1982): Nonformal Education and National Development. Nueva York: Praeger.

- y BOCK, C. M. (1989): “Educación no formal: política en los países en vías de desarrollo", en HUSEN, T.; POSTLETHWAITE, T. N. (dtres.): Enciclopedia Internacional de la Educación. Barcelona: Vicens-Vives/ MEC, págs. 1855-1860.

BOPP, M. (1994): “The Illusive Essential: Evaluating Participation in Non-Formal Education and Community Development Processes", en Convergence, vol 27, no 1, págs. 23-45.

BREMBECK, C. (1976): "Introducción", en BREMBECK, C y THOMPSON, T. J. (Eds): Nuevas estrategias para el desarrollo educativo. Investigación Intercultural de alternativas no formales. Buenos Aires: Guadalupe, págs. 9-16.

- y GRANDSTAFF, M. (1973): Non-formal Education as an Alternative to Schooling. East Lansing, Michigan State University.

CAHANE, R. (1994): "Changing Concepts of Youth; The Origins and Development of Informal. Paper presented at the Israel- Germany Workshop: Patterns of Transition and Identity Formation of Adolescents. Jerusalem, 3-5 April, 1994.

CALLAWAY, A. (1976): "Fronteras de la educación extra escolar", en BREMBECK, C. S.; THOMPSON, T. J.: Nuevas estrategias para el Desarrollo Educativo. Investigación Intercultural de alternativas no formales. Buenos Aires: Guadalupe, págs. 31-46.

CARIOLA, P. (1991): "Panorama de la educación no formal: un intento clarificador", en AA.VV.: La educación no formal una prioridad de futuro. Madrid: Fundación Santillana, págs. 153-155.

CARRON, G. y CARR-HILL, R. A. (1991): Non-Formal Education: Information and Planning Issues. París: Unesco/ International Inst. for Educational Planning.

CIRIGLIANO, G. (1982): La educación abierta. Buenos Aires: El Ateneo.

COLOM, A. J. et al. (1987): Modelos de intervención socioeducativa. Madrid: Narcea.

- (1992): “Estrategias metodológicas en la educación no formal", en SARRAMONA, J. (ed): La educación no formal. Barcelona: Ceac, págs. 51-74.

- (1998): "Planificación de la educación no formal", en SARRAMONA, J.; VÁZQUEZ, G.; COLOM, A. J.: Educación no formal. Barcelona: Ariel, págs. 165-200.

- (coord.): Teorias e instituciones contemporáneas de la educación. Barcelona: Ariel,

COOMBS, Ph H. (1970): What is Educational Planning? Cuaderno no 1, Elementos de Planificación educativa. París: IIEP/ UNESCO.

- (1970 a): "The Need for a New Strategy of Educational Development", Comparative Education Review, vol. 14, nº 1, págs. 75-89.

- (1971): La crisis mundial de la educación. Barcelona: Península.

- (1971 a): Outline of Research Project on Non-Formal Education for Rural and Agricultural Development. Essex, Connecticut: Consejo Internacional para el Desarrollo educativo.

- (1973): "Should One Develop Nonformal Education?", en Prospects, vol. 3, nº 3, págs. 287-306.

- (1974 a): "Where Should Agricultural Education Go From Here?", Indian Journal of Adult Education, vol. 35, no 8, págs. 14-18.

- (1974 b): Major problems facing educational planning in the next decade. The fundamentals of educational Planning. París: UNESCO.

- (1975): "Opportunities in Non-formal Education for Rural Development", Indian Journal of Adult Education, vol 36, $\mathrm{n}^{\circ} 7$, págs. 12-13. 
- (1975 a): "Education for Rural Development: Some Implications for Planning", Paper presented at the IIEP Seminar on "The Planning Problems in Rural Education". UNESCO/International Inst. for Educational Planning.

- (1976): "Como planificar la educación no formal", en BREMBECK, C. S.; THOMPSON, T. J.: Nuevas estrategias para el Desarrollo Educativo. Investigación Intercultural de alternativas no formales. Buenos Aires: Guadalupe, págs. 199-216.

- (1976 a): "Non formal Education - Myths, Realities and Opportunities", Comparative Educational Review, vol 20, no 3, págs. 281-293.

- (1981): "Meeting the basic needs of the rural poor - the integrated, Community - based Approach", en International Review of Modern Sociology, vol. 11, n² 1-2, págs. 347-351.

- (1981 a): Future Critical World Issues In Education: A Provisional Report Of Findings. Essex, Conn.: ICED.

- (1981 b): New Strategies for Improving Rural Family Life. Essex, Conn.: International Council for Educational Development.

- (1982): "Critical world Educational Issues of the Next Two Decades", en International Review of Education, vol. 28, n⿳o 2, págs. 143-157.

- (1982 a): "The importance of Education for Change of Front-Line Workers and Villagers, en Convergence, vol 15, no 4, págs. 32-37.

- (1985): La crisis mundial en la educación. Perspectivas actuales. Madrid: Santillana.

- (1985 a): "Sugerencias para una política realista de la educación de adultos", en Perspectivas, vol. $\mathrm{XV}, \mathrm{n}^{\circ} 1$, págs. 29-42.

- (1989): "Educación formal y no formal: estrategias para el futuro", en HUSEN, T. \& POSTLETHWAITE, T. N. (dtres); Enciclopedia Internacional de la Educación. Barcelona: Vicens-Vives, MEC, pp. 1818-1821.

- (1990): "Nueve lecciones sobre inovación educativa", en Profesiones y empresas, $\mathrm{n}^{\circ} 2$, págs. 66-68.

- (1991): "El futuro de la educación no formal en un mundo cambiante», en AA.VV.: La educación no formal, una prioridad de futuro. Madrid: Fundación Santillana págs. 43-52.

- (1991 a): “Políticas educativas globales y estrategias de planificación”, en AA.VV. (1991): La educación no formal. Una prioridad de futuro. Madrid: Fundación Santillana, págs. 73-75.

- (1992): "World Literacy in the Year 2000- Preface", en Annals of the American Academy of Political and Social Science, vol. 520, págs. 9-11.

- y AHMED, M. (1974): Attacking Rural Poverty: How Nonformal Educacion Can Help. A Research Report for the World Bank Prepared by the International Council for Educational Development. Essex, Conn. (Versión traducida: La lucha contra la pobreza rural. El aporte de la educación no formal. Publicado para el Banco Mundial por Editorial Tecnos, Madrid, 1975).

- y AHMED, M. (1974 c): Building New Educational Strategies to Serve Rural Children and Youth. Second Report on a Research Study for UNICEF prepared by the International Council for Educational Development.

- y PROSSER, R.C., M. AHMED (1973 a): New Paths To Learning: For Rural Children and Youth. International Council for Educational Development Publications, Essex, Connecticut (Report for United Nations Children's Fund. New York, N.Y.

DAVE, R. H. et al. (1990): Meeting The Basic Learning Needs Of Out-Of-Scbool Children: NonFormal Approaches. UNESCO.

DELORS, J. (1996): La educación encierra un tesoro. Unesco. Santillana. Madrid. 
DOVEY, K. (1995): «Making Up the Deficit: A South African Non-Formal Education Project for Industrial Personnel, en International Journal of Lifelong Education, vol 14, no 1 , págs. 39-50.

DUKE, C. (ed.) (1985): Combatting Poverty through Adult Education: National Development Strategies. Dover, N. H.: Croom Helm.

EKSTRAND, L. H. (1989): "The Future of Non-Formal Education for Women in India: Problems and Sugfestions for a Fruitful Development", en Women and Literacy: Yesterday, Today and Tomorrow. Hasselby Symposium on Women and Literacy, Nordic Association for the Study of Education in Developing Countries, Estocolmo.

ELLIS, P. (1994): Non-Formal Education and Empowerment of Women: Report of a Study in the Caribbean. Eric Report (ED392960).

ESCÁMEZ SÁNCHEZ, J.; PÉREZ ALONSO-GETA, P. (1992): «Planificación de programas en educación no formal", en SARRAMONA, J. (ed): La educación no formal. Barcelona: Ceac, págs. 75-90.

ETXEBERRIA, F. (dir.) (1989): Pedagogía social y educación no escolar. Ed. Univ. del País Vasco.

EVANS, D. R. (1981): The Planning of Non-Formal Education. París: Unesco.

FAURE, E. et al. (1973): Aprender a ser. Madrid: Alianza Universidad.

FERMOSO, P. (1994): "La educación no formal: fuera de la escuela y de la familia", en FERMOSO, P.: Pedagogía Social. Barcelona: Herder, págs. 109-125.

FOX, H. et al. (1991): Nonformal Education Training Module. Amherst, MA.: Institute for Training and Development.

FRABBONI, F. (ed.) (1989): Il sistema formativo integrato. Teramo: EIT.

FURTER, P. (1980): Les systemes de formation dans leurs contextes. Berna: Peter Lang.

- (1983): Les espaces de la formation. Laussanne: Presses Polytechniques Romandes.

GARCÍA CARRASCO, J. (1988): "Agentes de la educación formal, no formal e informal", en Symposium Internacional de filosofía de l'educació. Bellaterra: Universitat Autònoma de Barcelona, págs. 127-155.

GARCÍA GARRIDO, J. L. (1991): "Diez tesis sobre la educación abierta (también llamada no formal)", en AA.VV. (1991): La educación no formal, una prioridad de futuro. Madrid: Fundación Santillana, pp. 159-160.

- (1991): "Educación para todos y educación no formal en el marco de una Europa Unida", en AA.VV.: La educación no formal, una prioridad de futuro. Madrid: Fundación Santillana, págs. 53-60.

GONZALES, M. A. C. T. y PIJANO, M. A. CONCEPCIÓN V. (1997): "Non-formal Education in the Philippines: A Fundamental Step towards Lifelong Learning, en: AA.VV. (1997): Lifelong Learning: Policies, Practices, and Programs.

GRANDSTAFF, M (1976): “Non-formal Education: Some indications for its use», en Comparative Educational Review, vol. 20, nº 3, págs. 294-304.

- (1978): “L'education non-formelle comme concept”, en Perspectives, vol VIII, nº 2, págs. 195-200.

- et al. (1974): Historical Perspectives in Non-Formal Education. East Lansing, Michigan State University

GUTTMAN, C.; KOSONEN, K. (1994): Within Reach: The Story of PROPEL, a Non-Formal Education Project for Rural Children in India. París: Unesco.

GUYOT, J. F. (1976): «QQué beneficios reporta desformalizar la educación y a quienes favorece?, en BREMBECK, C. S.; THOMPSON, T. J.: Nuevas estrategias para el Desarrollo 
Educativo. Investigación Intercultural de alternativas no formales. Buenos Aires: Guadalupe, págs. 179-188.

HADDAD, W. D (1991): "Vías para la democratización de la educación de adultos", en AA.VV.: La educación no formal, una prioridad de futuro. Madrid: Fundación Santillana, págs. 129-130.

- (1991 a): "Desarrollo económico y demandas de educación" en AA.VV.: La educación no formal, una prioridad de futuro. Madrid: Fundación Santillana, págs. 69-72.

- (1991 b): “Educación para todos en las sociedades modernas", en AA.VV.: La educación no formal, una prioridad de futuro. Madrid: Fundación Santillana, págs. 29-36.

HAMADACHE, A. (1991): "Non-Formal Education: A Definition Of The Concept And Some Examples", en Prospects, vol 21, no 1, págs. 111-124.

HARBISON, F. H. (1976): "Recursos humanos y educación no formal", en BREMBECK, C. S.; THOMPSON, T. J.: Nuevas estrategias para el Desarrollo Educativo. Investigación Intercultural de alternativas no formales. Buenos Aires: Guadalupe, págs. 20-30.

HEIMLICH, J. E. et al. (1996): "Adult Learning in Nonformal Institutions", en ERIC Digest, nº 173.

KELLER, D.; DROR, I. (1995): "Planning Non-Formal Education Curricula: The Case of Israel". Paper presented at the Annual Meeting of the American Educational Research Association, San Francisco, CA, April 18-22, 1995.

KING, K. (1982): "Formal, Nonformal and Informal Learning: Some north-south contrast", en International Review of Education, vol 28, ํㅡㄹ 2, págs. 177-187.

LA BELLE, Thomas J. (1976): Nonformal Education and Social Change in Latin America. UCLA Latin American Center Publications. University of California, Los Angeles. (Versión traducida, 1980: Educación no formal y cambio social en América Latina. México: Nueva Imagen).

- (1981): "An introduction to the Nonformal Education of Children and Youth", en Comparative Education Review, vol 25, n² 3, págs. 313-329.

- (1982): "Formal, Nonformal and Informal Education: a Holistic Perspective in Lifelong Learning", en International Review of Education, vol 28, nº 2, págs. 159-175.

- (1984): "Liberation, Development, and Rural Nonformal Education", en Anthropology and Education Quartely, vol 15, nº 1, págs. 80-93.

LENGRAND, P. (1982): "Structures de l'apprentissage dans les pays de l'Europe occidentales", en International Review of Education, vol 28, nº 2, págs. 189-207.

LOWE, J. (1989): "Educación no formal postsecundaria", en HUSEN, T.; POSTLETHWAITE, T. N. (dtres.): Enciclopedia Internacional de la Educación. Barcelona: Vicens Vives/ MEC, págs. 1844-1847.

MORPHET, A. R. (1986): "Currículum Issues in Non-formal Education: A Case Study an d Interpretation", en International Journal of Lifelong Education, vol 5, nº 2, págs133-151.

NARANG, R. H. (1992): "Social Justice and Political Education through Non-Formal Education", en International Review of Education, vol. 38, nº 5, págs. 542-46.

NATIONAL INST. FOR EDUCATIONAL RESERCH (1987): Non-Formal Education in Asia and the Pacific. Tokyo: National Institute for Educational Research.

NIEHOFF, R. O. (1977): Report on Conference and Workshop on Non-formal Education and the Rural Poor. East Lansing: Michigan State University.

NON-FORMAL EDUCATION INFORMATION CENTER (1981): Children: Health, Education and Change. A Selected, Annotated Bibliogapby. East Lansing: Michigan State University, Non-formal Education Information Center. 
NÚÑEZ CUBERO (ed.) (1993): Metodologias de investigación en la educación no formal. Sevilla: Preu Spínola.

O.C.D.E. (1996): Lifelong Learning for All. Meeting of the Education Committee at Ministerial Level (4th, Paris, France, January 16-17, 1996). Paris: Organisation for Economic Cooperation and Development.

ORDEN, A De La (1991): "La educación no formal en una sociedad compleja", AA.VV.: La educación no formal, una prioridad de futuro. Madrid: Fundación Santillana, págs. 157-158.

PAIN, A. (1990): Education informelle. Les effets formateurs dans le quotidien. París: L'Harmattan.

PAULSTON, R. (1972): Non-formal Education, an Annotated International Bibliography of the Non-School Sector. New York: Praeger Publishers.

- (1976): "Alternativas educativas no formales", en BREMBECK, C. S.; THOMPSON, T. J.: Nuevas estrategias para el Desarrollo Educativo. Investigación Intercultural de alternativas no formales. Buenos Aires: Guadalupe, págs. 100-128.

- (1980): “Education as Anti-Structure: Non-Formal Education in Social and Ethnic Movements", en Comparative Education, vol 16, nº 1, págs. 55-66.

PERCY, K. et al. (1994): Self-Directed Learning Among Adults: The Challenge for Continuing Educators. Association for Lifelong Learning, England.

PÉREZ SERRANO, G. (et al.) (1992-93): "La investigación-acción en la educación formal y no formal", en Enseñanza. Anuario Interuniversitario de Didáctica, nos 10-11, págs. 177-198.

POWER, C. (1991): "Educación no formal y democratización de oportunidades", en AA.VV.: La educación no formal, una prioridad de futuro. Madrid: Fundación Santillana págs. 131-132.

- (1991): "Enfoques no formales para la consecución de la educación para todos", en AA.VV.: La educación no formal, una prioridad de futuro. Madrid: Fundación Santillana págs. 147-151.

PUIG, J. Mª y TRILLA, J. (1985): Pedagogia de l'oci. Barcelona: Ceac.

QUEENEY, D. S. (ed.) (1996): A Learning Society: Creating an America that Encourages Learning throughout Life. Wahington, D.C.: National Association of State Universities and Land Grant Colleges.

QUINTANA, J. M a (1976): "La educación informal y la escuela en la sociedad del futuro", en Revista de Ciencias de la Educación, año XXII, no 85, págs. 17-29.

- y otros (1991): Iniciativas sociales en educación informal. Madrid: Rialp.

RADCLIFFE, D. J.; COLLETTA, N. J. (1989): “Educación no formal”, en HUSEN, T. \& POSTLETHWATE, T. N. (dtres): Enciclopedia Internacional de la Educación. Barcelona: Vicens Vives/MEC, págs. 1837-1842.

REED, H. B. (1987): "Confligting Images of Nonformal Education", en Lifelong Learning, vol. $10, \mathrm{n}^{\circ} 6$, págs. $23-25$.

REINHOLD, A. J. (1993): Working with Rural Communities in Nepal: Some Principles of NonFormal Education Intervention. Action Research in Family and Early Chilhood. Westport, CT: Save The Children Report.

RIEZEN, K. Van (1996): «Non-Formal Education and Community Development: Improving the Quality", en Convergence, vol 29, $\mathrm{n}^{\mathrm{O}} 1$, págs. 82-95.

SALONIA, ANTONIO F. (1993): "Educacion abierta y plural y politicas globalizadoras", en Revista Iberoamericana de Educaciôn, 1993, (3): 123-144

SÁNCHEZ FIERRO, J. (1991): "Educación, vida activa y trabajo”, en AA.VV.: La educación no formal, una prioridad de futuro. Madrid: Fundación Santillana, págs. 77-80. 
$M^{2}$. INMACULADA PASTOR HOMS

ÁMBITOS DE INTERVENCIÓN EN EDUCACIÓN NO FORMAL. UNA PROPUESTA TAXONÓMICA

SANTOS REGO, M. A. (et al.) (1992): «Hacia la mejora de la calidad educativa a través de los procesos de educación no formal", en Bordón, vol. 44, nº 3, págs. 265-274.

SANZ, F. (1990): Educación no formal en la España de la posguerra. Madrid: Univ. Complutense.

SARRAMONA, J. (1981-82): «Principios que justifican la metodología no formal en la educación de adultos", en Educar, no 1 , págs. 49-60.

- (ed.) (1992): La educación no formal. Barcelona: Ceac.

- (1998): "La evaluación de programas en educación no formal", en SARRAMONA, J.; VAZQUEZ, G.; COLOM, A. J.: Educación no formal. Barcelona: Ariel. págs. 201-233.

- VÁZQUEZ, G. y ÚCAR, X. (1992): "Evaluación de la educación no formal”, en SARRAMONA, J. (ed): La educación no formal. Barcelona: Ceac. págs. 91-125.

- VÁZQUEZ, G. y COLOM, A. J. (1998): Educación no formal. Barcelona: Ariel.

SCHWARTZ, B. (1969): "Formal and informal education", en BEREDAY, G.Z.F. (ed.): Essays on World Education. The Crisis of Suply and Demand. Nueva York: Oxford University Press, págs. 153-166.

SCRIBNER, S. y COLE, M. (1973): "Cognitive consequences of formal and informal education", en Science, $\mathrm{n}^{\mathbf{0}} 182$, noviembre 1973, pp. 553-559 (Versión traducida en Infancia y aprendizaje, $\mathrm{n}^{\circ} 17,1982$, pp 3-18).

SCURATI, C. (1986): L'educazione extraescolastica. Brescia: La Scuola.

SHOFTHALER, T (1981): "Educación informal”, en Educación, vol. 24, págs. 89-107.

SIMKINS, T. (1977): Non-Formal Education and Development. Manchester: University of Manchester.

SRINIVASAN, L. (1989): “Educación no formal: enseñanza” en HUSEN, T. \& POSTLETHWATE, T. N. (dtres): Enciclopedia Internacional de la Educación. Barcelona: Vicens Vives/MEC págs. 1852-1855.

SVENSSON, A. (1992): Non-Formal Education- A Worthwhile Alternative To The Formal Education In India? Case Studies from Ganjam, Orissa. Lund University (Sweden). Malmo School of Education.

THOMPSON, J.D.E. (1995): Curriculum development in Non-formal Education. Nairobi (Kenya): African Association for Literacy and Adult Education.

TORRES, C. A. (1990): The politics of nonformal education in Latin America. Nueva York: Praeger.

TOURIÑAN, J. (1983): “Análisis teórico del carácter 'formal', 'no formal' e 'informal' de la educación", Papers d'Educació, no 1, págs. 105-127.

TRILLA, J. (1984): “La educación no formal", en SANVISENS, A. (dtor): Introducción a la Pedagogia. Barcelona: Barcanova, págs. 337-365.

- (1985): La educación fuera de la escuela. Enseñanza a distancia, por correspondencia, por ordenador, radio, video y otros medios no formales. Barcelona: Planeta.

- (1986): La educación informal. Barcelona: PPU.

- (1988): "Animación sociocultural, Educación y Educación no formal", en Educar, nº 13, págs. 17-41.

- (1992): "La educación no formal. Definición, conceptos básicos y ámbitos de aplicación", en SARRAMONA, J. (ed): La educación no formal. Barcelona: Ceac, págs. 9-50.

- (1993): La educación fuera de la escuela. Ámbitos no formales y educación social. Barcelona: Ariel.

- (1993): Otras educaciones: animación sociocultural, formación de adultos y ciudad educativa. Barcelona: Anthropos. 
ÁMBITOS DE INTERVENCIÓN EN EDUCACIÓN NO FORMAL. UNA PROPUESTA TAXONÓMICA

UNESCO (1990): Declaración Mundial sobre Educación para todos. Satisfacción de las necesidades básicas de aprendizaje (Declaración de Jomtien, Tailandia). Madrid: MEC.

VÁZQUEZ, G. (1998): "La educación no formal y otros conceptos próximos", en SARRAMONA, J.; VÁZQUEZ, G.; COLOM, A. J.: Educación no formal. Barcelona: Ariel, págs. 11-28.

WARD, T.W. (1974): Effective Learning in Non-Formal Education. East Lansing, Michigan State University.

YOYOLE, E. A. (1987): "Relationship between the Work of Teachers in Nonformal settings and in Schools", en International Review of Education, vol. 33, no 3, págs. 339-350. 